10

\title{
Бесполяризаторные акустооптические монохроматоры
}

\author{
() В.М. Епихин, ${ }^{1}$ Ф.Л. Визен, ${ }^{2}$ З.А. Магомедов, ${ }^{2}$ Л.Л. Пальцев ${ }^{1}$ \\ ${ }^{1}$ Всероссийский научно-исследовательский институт фризико-технических и радиотехнических измерений, \\ 141570 Менделеево, Московская обл., Россия \\ ${ }^{2}$ АО „Сигма-Оптик“, \\ 124460 Москва, Зеленоград, Россия \\ e-mail: epikvm@mail.ru
}

(Поступило в Редакцию 17 мая 2017 г.)

Исследованы монохроматоры на основе неколлинеарного акустооптического фильтра без внешних поляризаторов, в которых в качестве элемента для выделения полезного дифрагировавшего светового пучка использованы: 1) пространственный фильтр-телескоп; 2) повернутая в плоскости дифракции выходная грань кристалла фильтра. Во втором случае для компенсации дисперсии кристалла акустооптического фильтра использована корректирующая призма из того же кристалла, установленная за выходной гранью фильтра по ходу отфильтрованного светового пучка. В результате увеличивается коэффициент пропускания монохроматора при эффективной компенсации углового дрейфа отфильтрованного светового пучка, упрощается конструкция монохроматора, а также уменьшаются его размеры.

DOI: $10.21883 /$ JTF.2018.07.46180.2336

\section{Введение и постановка задачи}

Важной задачей прикладной спектроскопии является увеличение коэффициента пропускания монохроматора - отношение интенсивностей прошедшего через монохроматор и падающего на него световых пучков.

Акустооптический (AO) монохроматор, помимо дисперсионного элемента (АО фильтр (АОФ)), содержит систему выделения дифрагировавшего светового пучка. Так как при АО фильтрации имеет место анизотропная дифракция света, обычно используют поляризационное разделение пучков с внешними скрещенными поляризаторами [1]. Часто в качестве последних используют поляризаторы Глана-Тейлора, каждый из которых содержит две призмы из монокристаллического кальцита, разделенные воздушным промежутком. Схема АО монохроматора с внешними поляризаторами приведена на рис. 1. Такая конструкция обеспечивает высокий

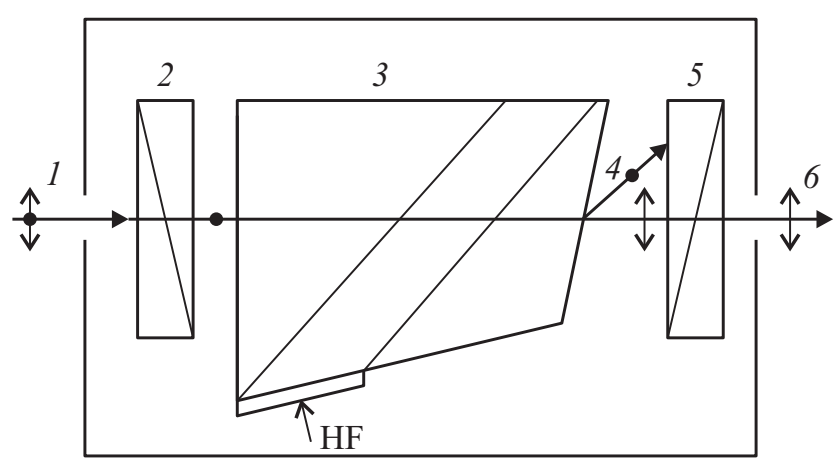

Рис. 1. Схема $\mathrm{AO}$ монохроматора с внешними поляризаторами: 1 - исходный неполяризованный пучок, 2,5 - внешние поляризаторы, 3 - АОФ, 4 - недифрагировавший пучок, 6 - плоскополяризованный дифрагировавший выходной пучок $(\mathbf{o} \rightarrow \mathbf{e}), \mathrm{HF}-$ управляющий высокочастотный вход АОФ. контраст (отношение фотосигналов при наличии управляющего ВЧ-сигнала и его отсутствии) и малые размеры монохроматора. Ее недостатки - использование дорогостоящих поляризаторов, низкий коэффициент пропускания, обусловленный поглощением в поляризаторах и отражениями проходящего светового пучка от большого числа оптических плоскостей $(n=10)$.

Иногда используют пространственное разделение пучков на угол дифракции $\Delta$. Ранее в работе [2] для наиболее эффективного выделения полезного пучка в этом случае было предложено использовать пространственный фильтр. На рис. 2 представлена схема АО монохроматора без внешних поляризаторов с пространственным фильтром-телескопом. Диаметр отверстия диафрагмы $D=2 F \cdot \operatorname{tg}(\Delta \eta / 2)$, где $F-$ фокусное расстояние линз телескопа, $\Delta \eta-$ угловая апертура АОФ. Недостатки этой схемы: значительное число отражающих поверхностей $(n=6)$ и необходимость точной юстировки оптической системы монохроматора.

Следует отметить, что по данной схеме было изготовлено около 1000 экземпляров АО монохроматоров, которые успешно работали в течение 10 лет (а некоторые продолжают работать в настоящее время) в составе оптических спиртомеров „ИКОНЭТ-МП“, предназначенных для измерения объемной концентрации этилового спирта в водно-спиртовых и многокомпонентных спиртосодержащих растворах и установленных на линиях разлива большинства отечественных ликеро-водочных заводов в соответствии с программой ЕГАИС (единая государственная автоматизированная информационная система контроля расхода этанола) [3-6].

Цель настоящей работы - рассмотреть новый АО монохроматор без внешних поляризаторов, в котором выделение полезного дифрагировавшего светового пучка происходит на наклоненной в плоскости дифракции 


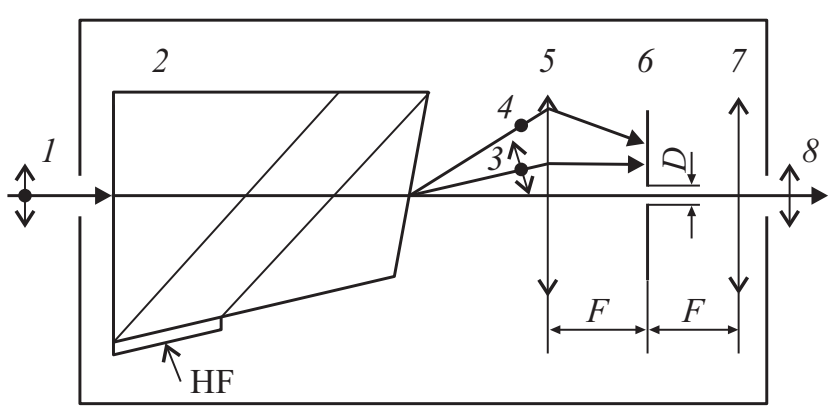

Рис. 2. Схема АO монохроматора с пространственным фильтром-телескопом: 1 - исходный неполяризованный пучок, 2 - АОФ, 3 - недифрагировавший пучок, $4-$ плоскополяризованный дифрагировавший пучок, не являющийся полезным $(\mathbf{e} \rightarrow \mathbf{o}), 5,7-$ линзы с фокусным расстоянием $F$, 6 - диафрагма с диаметром отверстия $D, 8$ - плоскополяризованный дифрагировавший выходной пучок $(\mathbf{o} \rightarrow \mathbf{e})$.

выходной грани АОФ, а также определить его преимущества по сравнению с монохроматорами, построенными по известным схемам. АО монохроматоры, в которых отсутствуют внешние поляризаторы, по нашему мнению, целесообразно называть бесполяризаторными.

\section{Описание работы бесполяризаторного монохроматора с разделением световых пучков на выходной грани АОФ}

Схема предлагаемого АО монохроматора изображена на рис. 3. Диаграмма волновых векторов акустической волны, а также волновых векторов падающего и дифрагировавших световых пучков в одноосном двулучепреломляющем положительном $\left(n_{e}>n_{o}\right)$ кристалле парателлурита $\left(\mathrm{TeO}_{2}\right)$, иллюстрирующая $\mathrm{AO}$ дифракцию в предлагаемом монохроматоре, дана на рис. 4 [7].

Исходный неполяризованный световой пучок, попадая в двулучепреломляющий кристалл, разбивается на обыкновенный и необыкновенный пучки (волновые векторы о и е соответственно). Волновой вектор о имеет угол $\theta_{o} \mathrm{c}$ осью $z$. В результате дифракции на акустической волне с волновым вектором q, имеющим угол $\gamma$ с осью [110], в кристалле АОФ распространяются недифрагировавшие пучки о и е, а также дифрагировавшие пучки $(\mathbf{e} \rightarrow \mathbf{o})$ и $(\mathbf{o} \rightarrow \mathbf{e})$, причем среди перечисленных пучков полезным является пучок $(\mathbf{0} \rightarrow \mathbf{e})$, так как только для векторов о и $(\mathbf{o} \rightarrow \mathbf{e})$ выполняется условие большой угловой апертуры АОФ [1].

Как видно из рис. 3, выделение полезного дифрагировавшего светового пучка происходит на выходной грани АОФ благодаря тому, что пучки 4 (недифрагировавшие части пучков о и е) и 6 (дифрагировавший пучок $(\mathbf{e} \rightarrow \mathbf{o})$, не являющийся полезным) испытывают эффект полного внутреннего отражения (ПВО). Напротив, дифрагировавший полезный пучок 6 проходит через выходную грань АОФ, так как волновой вектор $(\mathbf{0} \rightarrow \mathbf{e})$ при анизотропной дифракции изменяет свою ориентацию на угол $\Delta$, в результате условие ПВО на выходной грани АОФ для него нарушается. Ориентацию выходной грани АОФ определим углом $\varphi$ в плоскости дифракции. Угол $\varphi$ зависит от спектрального диапазона монохроматора $\left(\lambda_{1}-\lambda_{2}\right)$, ориентации векторов о, $\mathbf{e}, \mathbf{q}$ в кристалле, а также показателей преломления $n_{e}, n_{o}$ парателлурита.

Расчеты показали, что указанное условие выделения пучка $(\mathbf{o} \rightarrow \mathbf{e})$ выполняется в определенном интервале углов падения исходного пучка на входную грань АОФ $\Delta \alpha$, величина которого составляет единицы градусов, что представляет практический интерес. За пределами $\Delta \alpha$ это условие нарушается, а именно: либо через АОФ начинают проходить дополнительные световые пучки, либо не проходят никакие пучки вовсе. Следовательно, для корректной работы АО монохроматора

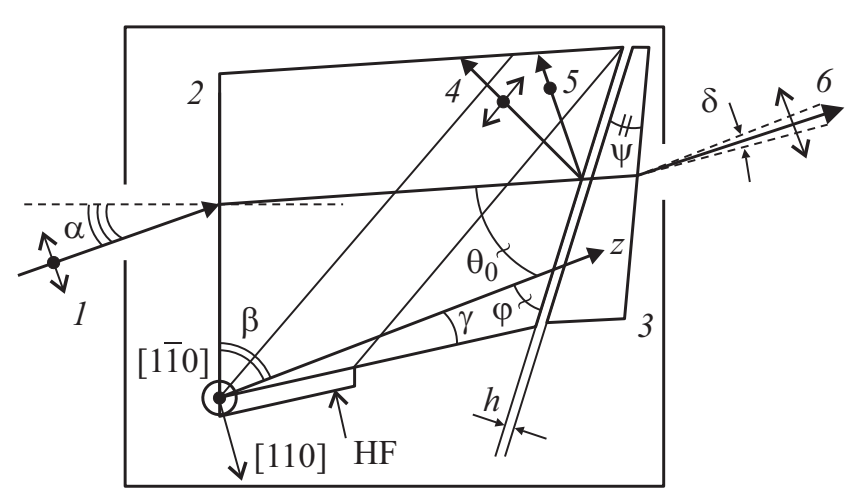

Рис. 3. Схема $\mathrm{AO}$ монохроматора с повернутой в плоскости дифракции выходной гранью АОФ и корректирующей призмой: 1 - исходный неполяризованный пучок, $2-\mathrm{AOФ,}$ 3 - корректирующая призма, 4 - недифрагировавший пучок, 5 - плоскополяризованный дифрагировавший пучок, не являющийся полезным $(\mathbf{e} \rightarrow \mathbf{o}), 6-$ плоскополяризованный дифрагировавший выходной пучок $(\mathbf{o} \rightarrow \mathbf{e}), \delta-$ спектральный угловой дрейф дифрагировавшего пучка.

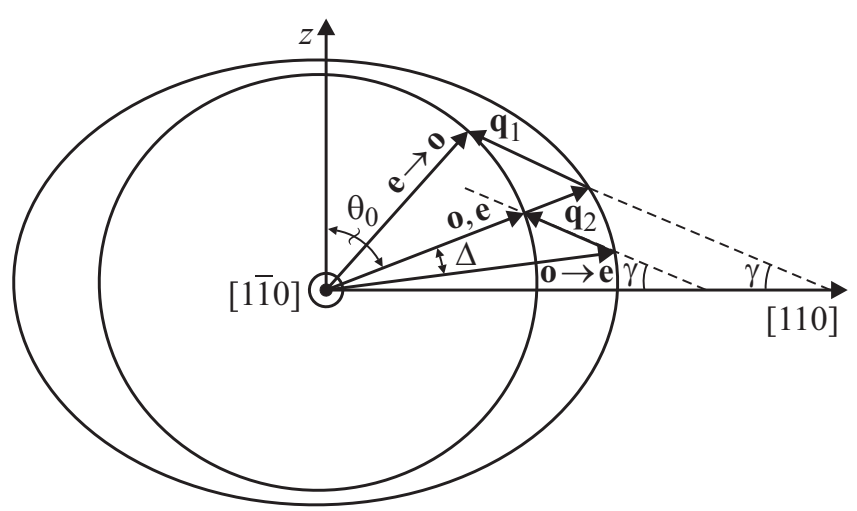

Рис. 4. Диаграмма волновых векторов падающей $(\mathbf{0}, \mathbf{e})$ и дифрагировавших $(\mathbf{e} \rightarrow \mathbf{0}, \mathbf{0} \rightarrow \mathbf{e})$ световых волн, а также акустической волны q. $\theta_{0}-$ угол падения, $\Delta-$ угол дифракции, $\mathbf{q}_{1} \| \mathbf{q}_{2}$ (в общем случае $\left.\mathbf{q}_{1} \neq \mathbf{q}_{2}\right)$. 
Примеры бесполяризаторного АО монохроматора на $\mathrm{TeO}_{2}$ по схеме рис. 3 для нормального (вариант 1) и наклонного (вариант 2) падения пучка на входную грань

\begin{tabular}{c|c|c|c|c|c|c|c|c|c}
\hline Вариант & Спектральный диапазон, $\mathrm{nm}$ & $\Delta \alpha,{ }^{\circ}$ & $\alpha_{o},{ }^{\circ}$ & $\beta,{ }^{\circ}$ & $\gamma,{ }^{\circ}$ & $\theta_{o},{ }^{\circ}$ & $\varphi,{ }^{\circ}$ & $\psi,^{\circ}$ & $\delta,^{\circ}$ \\
\hline 1 & $600-1100$ & \pm 1.8 & 0 & 67.9 & 10.6 & 22.1 & 40.15 & $20.80(22.90)$ & $0.0025(0.0950)$ \\
2 & $600-1100$ & $45.8-53.0$ & 49.4 & 48.1 & 10.6 & $22.4-21.7$ & 40.10 & 2.55 & 0.0300
\end{tabular}

Пр имечание. Значения параметров без скобок соответствуют геометрии с минимальным спектральным угловым дрейфом.

Значения параметров в скобках соответствуют геометрии „с неизменной траекторией пучка“.

входной пучок должен быть сформирован так, чтобы его расходимость не превышала $\Delta \alpha$.

При фильтрации оптических изображений для компенсации углового спектрального дрейфа $\delta$ дифрагировавшего светового пучка за выходной гранью АОФ по ходу светового пучка установлена призма из материала АОФ с углом $\psi$ между входной и выходной гранями, так что выходная грань АОФ и входная грань призмы параллельны. Для того чтобы эффект ПВО на задней грани АОФ для всех световых пучков, кроме полезного, не нарушался, воздушный промежуток между АОФ и призмой должен иметь толщину $h \gg \lambda$, где $\lambda-$ максимальная величина длины волны из спектрального диапазона фильтруемого излучения в воздухе. Величина угла $\psi$ зависит от направлений распространения акустического и светового пучков в АОФ, угла между оптическими осями кристаллов АОФ и призмы, а также показателей преломления $n_{e}, n_{o}$. Расчетным путем установлено, что существует единственное значение угла $\psi$, при котором спектральный угловой дрейф выходного светового пучка за призмой является минимальным для заданных значений спектрального диапазона и угловой апертуры $\Delta \alpha[8]$.

Следует также отметить, что существует значение $\psi$, при котором дифрагировавший световой пучок, выходящий из АОФ, распространяется квазипараллельно падающему (точная параллельность возможна только в одной точке спектрального диапазона АОФ). Такая геометрия „с неизменной траекторией пучка“ весьма удобна в ряде практических задач. Очевидно, что в этом случае спектральный угловой дрейф выходного пучка больше минимально возможного.

Как видно из рис. 3, в данном варианте монохроматора число отражающих поверхностей с корректирующей призмой минимально $(n=4)$, а поляризация полезного дифрагировавшего пучка лежит в плоскости преломления на выходной грани АОФ, что увеличивает коэффициент пропускания монохроматора [9].

\section{Результаты расчетов и их обсуждение}

В таблице в качестве примера приведены результаты расчета угловых параметров бесполяризаторного монохроматора для спектрального диапазона $\lambda_{1}=600 \mathrm{~nm}$, $\lambda_{2}=1100 \mathrm{~nm}$. Использованные в таблице обозначения определены на рис. 3,4. В представленных вариантах угловые апертуры АОФ и „внутреннего поляризатора“, которым служит выходная грань АОФ, равны, а их центры совмещены. Это обеспечивается следующей процедурой. Вначале решалось уравнение (1) относительно угла $\beta$ при фиксированных углах $\gamma$ и $\alpha_{o}$ :

$$
f\left(\lambda_{1}, \alpha_{o}+\Delta \alpha / 2\right)=f\left(\lambda_{1}, \alpha_{o}-\Delta \alpha / 2\right) .
$$

Это означает выбор центра угловой апертуры АОФ вблизи локального минимума $f\left(\lambda_{1}, \alpha\right)$ по углу $\alpha$. Отметим, что значение $\Delta \alpha$ в формуле (1) слабо влияет на результат, поэтому его начальный выбор может быть сделан на основе оценок. Результатом являются значения $\beta_{1}$ и $\beta_{2}$.

Далее решалась система уравнений (2) относительно угла $\varphi$ при фиксированных углах $\gamma$ и $\beta$ :

$$
\alpha_{1}=\alpha_{o}-\Delta \alpha / 2, \quad \alpha_{2}=\alpha_{o}+\Delta \alpha / 2,
$$

где $\alpha_{1}=\max \left[\alpha_{1}\left(\lambda_{1}\right), \alpha_{1}\left(\lambda_{2}\right)\right], \alpha_{2}=\min \left[\alpha_{2}\left(\lambda_{1}\right), \alpha_{2}\left(\lambda_{2}\right)\right]-$ начальное и конечное значения углового интервала, где „Внутренний поляризатор“ работает во всем выбранном спектральном диапазоне. Результатом являются значения $\varphi_{1,2}$ и $\Delta \alpha_{1,2}$.

В расчетах использовались формулы зависимости частоты настройки АОФ от геометрии волновых векторов $f(\lambda, \gamma, \theta)[10,11]$ и закон Снеллия [9] для границы воздух-парателлурит. При определении направлений распространения световых пучков использовались уравнения поверхностей волновых векторов в кристалле парателлурита. При вычислении угла $\psi$ при вершине корректирующей призмы оптические оси кристаллов АОФ и призмы полагались параллельными.

В первом варианте центральное направление совпадает с нормалью к входной грани АОФ и $\alpha_{o}=0$. Этот вариант имеет сравнительно небольшую угловую апертуру $\Delta \alpha= \pm 1.8^{\circ}$ и очень малый спектральный угловой дрейф дифрагировавшего пучка $0.0025^{\circ}$.

Во втором варианте центральное направление расположено под углом $\alpha_{o}=49.4^{\circ}$ к нормали. В этом случае угловая апертура увеличивается вдвое до 7.2॰ ${ }^{\circ}$ Вместе с тем спектральный угловой дрейф в такой угловой апертуре возрастает и составляет $0.0300^{\circ}$.

\section{Экспериментальные результаты}

Для эксперимента были изготовлены два бесполяризаторных АО монохроматора (АОМХ) „с неизмен- 


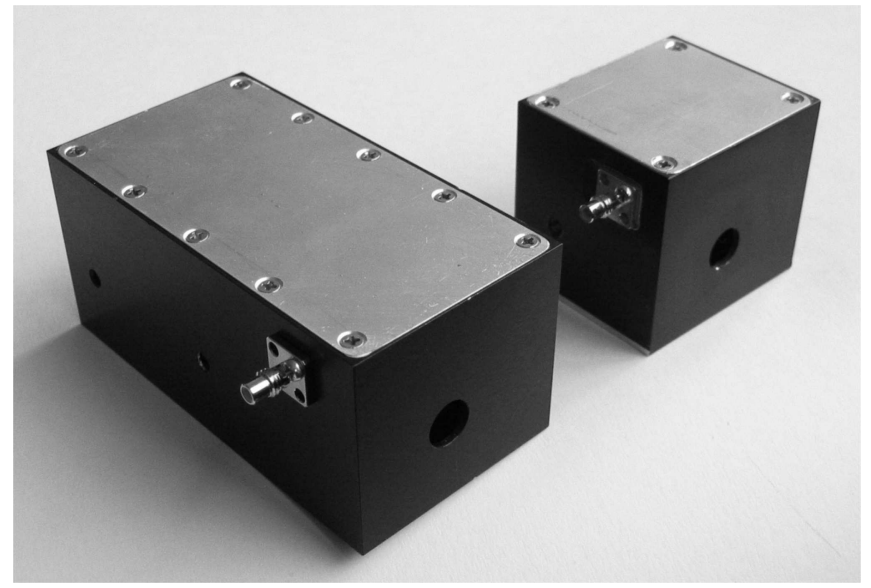

Рис. 5. Бесполяризаторные АО монохроматоры с различными способами выделения дифрагировавшего полезного светового пучка: слева - с помощью пространственного фильтра-телескопа (AOMX1), справа - на повернутой выходной грани АО фильтра (АОМХ2).

ной траекторией пучка“ на спектральный диапазон 600-1100 nm и шириной частотной аппаратной функции (по уровню 0.5 ) $\Delta f_{0.5} \sim 300 \mathrm{kHz}$ : АОМХ1 по схеме рис. 2 с пространственным фильтром и АOMX2 по схеме рис. 3 с разделением пучков на выходной грани. Фильтруемый световой пучок падал ортогонально входной грани АОФ. Изготовленные монохроматоры по параметрам были близки к варианту 1 таблицы.

Оба АОМХ работали в составе измерителя концентрации этилового спирта в многокомпонентных водноспиртовых растворах „ИКОНЭТ-МП“ [4]. Сравнение монохроматоров показало, что предложенный бесполяризаторный АОМХ2 имел повышенные на 30\% значения контраста и фотосигнала, при этом его размеры уменьшились более, чем вдвое. На рис. 5 для сравнения представлены изображения AOMX1 и АOMX2.

\section{Результаты и выводы}

1.Предложены, разработаны и экспериментально опробованы бесполяризаторные $\mathrm{AO}$ монохроматоры двух типов, в которых использованы различные устройства для выделения полезного дифрагировавшего светового пучка:

- пространственный фильтр-телескоп; АОФ.

- повернутая в плоскости дифракции выходная грань

2. Показано, что новый АО монохроматор с выделением дифрагировавшего пучка на выходной грани АОФ имеет повышенные значения контраста и коэффициента пропускания при существенно меньших габаритах.

3. Показано, что угловая апертура такого монохроматора может быть существенно увеличена при наклонном падении пучка на входную грань АОФ.
4. При использовании компенсирующей призмы, установленной за задней гранью АОФ по ходу светового пучка, такой АО монохроматор дает эффективную компенсацию спектрального дрейфа дифрагировавшего пучка, что важно при получении и обработке спектральных изображений.

\section{Список литературы}

[1] Chang I.C. // Appl. Phys. Lett. 1974. Vol. 25. N 7. P. 370-372.

[2] Епихин В.М., Визен Ф.Л. // Полезная модель № 16317. 20.07.2000.

[3] Визен Ф.Л., Газаров Х.В., Епихин В.М., Ермилов Ю.А., Жогун В.Н., Зайканова Г.И., Магомедов З.А., Ямников В.А. // Патент РФ № 2082967. 25.12.1992.

[4] Визен Ф.Л., Епихин В.М., Жогун В.Н., Магомедов З.А., Ямников В.А., Ермилов Ю.А., Зайканова Г.И. // Пищевая промышленность. 1996. № 10. С. 60-61.

[5] Жогун В.Н., Магомедов З.А., Визен Ф.Л., Епихин В.М., Аскеров Н.А., Косарев В.И., Евстифеев В.Ф., Пегов Г.М., Огородников А.А., Безносов Ю.В. // Полезная модель № 19586. 12.04.2001.

[6] Аскеров Н.А., Визен Ф.Л., Жогун В.Н., Магомедов 3.А. // Труды ВНИИФТРИ. Акустооптические, акустические и рентгено-спектральные методы и средства измерений в науке и технике. 2005. Вып. 48. № 140. С. 81-90.

[7] Епихин В.М. // Патент РФ № 2640123.23.03.2017.

[8] Епихин В.М., Калинников Ю.К. // ЖТФ. 1989. Т. 59. Вып. 2. С. 160-163.

[9] Ландсберг Г.С. Оптика. М.: Наука, 1976. 926 с.

[10] Епихин В.М., Визен Ф.Л., Пальцев Л.Л. // ЖТФ. 1987. Т. 57. Вып. 10. С. 1910-19017.

[11] Епихин В.М. // ЖТФ. 1995. Т. 65. Вып. 9. С. 71-75. 